\title{
IS A NEW DEAL IN THE CONTROL OF VENEREAL DISEASE NECESSARY?-1*
}

By I. N. ORPWOOD PRICE, M.R.C.S., L.R.C.P., D.P.H.

It has been felt for some years that all is not well with the present venereal diseases scheme. Planning for the future is in the air and some of us believe that the time is ripe for this Society as a whole first to consider and then to formulate reforms which would improve the working of the scheme, not only in war-time but also in the years to come. With this end in view Dr. Burgess and I have been asked to open this discussion. We do not anticipate that our opinions will be accepted in their entirety, but only hope that they will help to form the foundation of reforms which will be of benefit to our patients. I am sure that many members will wish to have their say also, so I propose to be brief.

As I see it, this discussion should turn on what is amiss and if I ignore the good points of the present veneral diseases scheme I hope no one will think that I have forgotten them.

\section{What is wrong with the present scheme?}

My first point is the lack of interest shown and of support given by most members of county councils and town councils, by medical officers of health, by our professional brethren and by the general public. It has taken a war of this magnitude to rouse many of these people from their apathy. Even now, how many councils have subcommittees formed for the purpose of dealing with venereal diseases; how many women councillors take any active interest in combating congenital syphilis; how many grants are given to encourage research work? Can anyone tell me why a doctor who devotes his energies to the diagnosis and treatment of venereal diseases is regarded by the general public as "just a pox doctor" and by his professional colleagues as not quite up to standard ? When I cogitate these matters I come to the conclusion that " the fault, dear Brutus, is not in our stars but in ourselves." We as a society have not organized ourselves effectively enough to allow not only our professional colleagues but also the lay public to realize that we perform, reasonably well, a function necessary for the well-being of the community, and are not a service ancillary to night clubs and similar institutions.

Secondly, why are the premises of some venereal diseases clinics, so cramped and ill-ventilated, situated in the basement of buildings? The interior arrangements of many clinics leave much to be desired-so much that some of us have to interview new patients in conditions which preclude any privacy. This scarcely facilitates our work.

Thirdly, the laboratory facilities of many clinics are poor. Often specimens have to be sent a considerable distance to be examined and complaints are heard that reports are not as reliable as they should be. In some clinics, clinicians who have had little or no training in pathological methods are expected to do at least some of the pathological work.

Fourthly, the prospects of medical officers engaged in this work are poor. I believe that better results would be obtained by manning the clinics with expert part-time medical officers who should be paid as experts and who should be allowed the 8 pportunity of private practice. I know that this is a contentious issue and trust that members of this Society will debate it in full. One thing seems certain and that is that when the treatment of venereal disease is only part of the medical officer's public health duties the venereal diseases clinic is apt to suffer in many instances. Whilst on the subject of staff I should like to protest against the regulation that lays down that any doctor who has spent 130 hours working in a venereal diseases clinic may then be regarded as being an expert in venereal diseases. Further, the appointing as directors of venereal diseases clinics of consultants who have had little or no training in these diseases and, worse, have little interest in them, should not be continued.

\footnotetext{
* An address to the Medical Society for the Study of Venereal Diseases, 27th November, 1943.
} 
Fifthly, I come to the vexed subject of the place of almoners in venereal diseases clinics. My personal experience is limited but as a result of it, such as it is, I cannot but declare that $I$ can see little useful purpose in employing almoners in these clinics. Theoretically, the probability of their doing any good seems to be remote. Most of the almoners I have met are unmarried and I think that none of my listeners (especially the ones who are married) will quarrel with me when I say that a peck of personal experience of the difficulties of married life is worth a bushel of theoretical training. So far as I can see the work of the almoner in the venereal diseases clinic is redundant because the personal side of the work appertains to the doctor and the clerical side can be done by an efficient clerical staff. I once read a book on social service in the venereal diseases clinic. According to this account I was forced to the conclusion that venereal diseases clinics seemed to be medically understaffed because the medical officers always appeared to be short of time and thus the almoner was forced to undertake many of the duties proper to the medical officer. I may be wrong but this was the impression that the book made on me. Home visiting, at least in urban areas, seems to be the least desirable of almoners' activities because once the connexion with the clinic is known, even with the best will in the world their efforts will fail. In practice, a good almoner does create a friendly atmosphere in the clinic and looks after the records, but I cannot help feeling that a good doctor and an efficient clerical staff could between them fulfil all functions.

These then are my five main criticisms of the present venereal diseases scheme. How are we to answer them?

\section{Suggestions for immediate improvement}

First, I would suggest that this Society at this meeting set up a small subcommittee consisting of from seven to nine members representative of all shades of opinion, in order to formulate a policy on the running of venereal diseases clinics and that this policy after approval by the whole Society be forwarded to appropriate authorities such as the Ministry of Health and local administrations. I would also suggest that this subcommittee be a permanent part of the Society and have the specific function of raising the standard of work of the venereal diseases service. Members of this subcommittee should retire after a definite term of office and new ones should be elected to take their places.

Secondly, my own suggestions for curing the troubles by which we are beset are as follows.

(1) A national venereal diseases service to be run by the local authorities through the Ministry of Health should be set up. Venereal disease is not confined by town or county boundaries and a parochial outlook should be avoided.

(2) The financial burden should be borne by the central government and the so-called block grant should be abolished as far as the venereal diseases service is concerned. I•cannot help feeling, although I have no information on the subject, that venereal disease is the Cinderella in many local budgets.

(3) Appointments to the venereal diseases service should be made by the central administration in conjunction with the local authorities.

(4) The local authorities should be responsible for the running of the clinics in their area and should report on them to the Ministry of Health.

(5) The whole country should be zoned according to the type and distribution of the population and a requisite number of clinics should be provided.

(6) The hours at the clinics should be fewer, thus avoiding waste of full-time man-hours of the medical staff and ancillary staff. I believe that a zoning scheme could be worked out so that the same staff could run several small clinics attached to a central parent clinic. The latter should be provided with beds and each clinic should be situated within the precincts of a general hospital or health centre.

(7) The medical staff should hold permanent appointments (subject to satisfactory service) and before appointment should have had at least three years' experience as clinical assistants in a venereal diseases clinic. They should be allowed personal freedom in the treatment of their patients. I think that patients 
can and should be seen by appointment. The medical officer should be assisted by clinical assistants and a system of promotion should be introduced.

(8) Laboratories run for this service should be staffed by properly trained persons who have had special experience in the practice of venereal diseases pathology.

These, then, are the main objects which I think we all should consider seriously. Dr. Burgess will give us the point of view of a medical officer engaged exclusively in public health work and I shall be extremely interested to hear what proposals he has to make.

\section{Now is the time for action}

Before I conclude, I should like to lay stress on the fact that if we wish to raise the standard of work in our speciality and the status of those engaged in it, now is the time to do so. I feel certain that if as a society we take no action now, we shall lose ground after the war and be regarded as of little or of no account. After the discussion therefore I shall propose the formation of a subcommittee for the purpose of formulating a policy for the conduct of the venereal diseases scheme.

\section{IS A NEW DEAL IN THE CONTROL OF VENEREAL DISEASE NECESSARY ?-2*}

\section{By J. A. BURGESS, M.D., D.P.H.}

Chief Venereal Diseases Officer and Assistant County Medical Officer of Health, West Riding, Yorkshire

In the introduction to the first number of The British Journal of Venereal Diseases it was stated that this Society confines its activities to the medical study of venereal diseases. Today's subject for discussion is probably one of the few exceptions to this rule. In advocating a new deal in venereal disease control, one must take into consideration also the administrative, social and moral aspects. It is right that we should break away from our study of the clinical effects of venereal diseases from time to time and ask ourselves whether we are in fact doing everything possible to deal with their menace.

In the first place, I do not wish to give the impression that I think our V.D. service is not a good one-far from it. Splendid work has been and is being accomplished. Some of us take the view however that improvements are necessary if we are to have a V.D. scheme which is second to none. In addition, more attention must be paid in the future to the prevention of these diseases.

Although a medical officer of health may be keenly desirous of providing his district with the best possible service, his activities are often limited by extraneous circumstances and the final decision on any matter rests with his committee. The individual members of the committee, having no practical experience of the work done at V.D. clinics and little more knowledge of venereal disease than the average layman, cannot be expected to assess the position to the best advantage. The result is that undue weight is often attached to the financial implications. Unfortunately, venereal disease has been a comparatively neglected branch of the public health services. For example, the Society of Medical Officers of Health has a dental officers' group, a fever hospital group, a maternity and child welfare group, a school medical service group and a tuberculosis group, but it has no venereal diseases group !

I understand that, under the block grant system, authorities are provided annually with a sum of money the amount of which is reviewed at the end of each five-year period. This sum goes toward the combined costs of the various public health services. Is it not possible then that one branch which is unpopular or to which some stigma is attached may receive less consideration than the others?

\footnotetext{
* An address to the Medical Society for the Study of Venereal Diseases, 27th November, 1943.
} 